\title{
Portadores da doença falciforme: reflexos da história da população negra no acesso à saúde
}

\author{
Carriers of sickle cell disease: reflections of the Black people history on \\ access to the health
}

\section{Portadores de la anemia de células falciformes: reflejos de la historia de la población negra en el acceso a la salud}

\author{
Edith Maria Barbosa Ramos ${ }^{1,2, a}$ \\ edithramosadv@yahoo.com.br | https://orcid.org/oooo-0001-6064-1879 \\ Paulo Roberto Barbosa Ramos ${ }^{1, b}$ \\ paulorbr@uol.com.br | https://orcid.org/oooo-0002-8966-8378 \\ Márcia Haydée Porto de Carvalho ${ }^{1, c}$ \\ marciahaydee@uol.com.br | https://orcid.org/0000-0002-0783-4302 \\ Delmo Mattos da Silva ${ }^{2, d}$ \\ delmomattos@hotmail.com | https://orcid.org/0000-0002-9074-2192 \\ Paulo Henrique de Freitas Dutra Júnior ${ }^{2, e}$ \\ paulojunior.dutra@gmail.com | https://orcid.org/oooo-0002-4133-1717

\footnotetext{
${ }^{1}$ Universidade Federal do Maranhão, Centro de Ciências Sociais, São Luís, MA, Brasil.

${ }^{2}$ Universidade CEUMA, Centro Universitário do Maranhão. São Luís, MA, Brasil.

a Doutorado em Políticas Públicas pela Universidade Federal do Maranhão.

b Doutorado em Direito Constitucional pela Pontifícia Universidade Católica de São Paulo.

c Doutorado em Direito pela Pontifícia Universidade Católica de São Paulo.

d Doutorado em Filosofia pela Universidade Federal do Rio de Janeiro.

e Graduando em Direito pelo Centro Universitário do Maranhão.
}

\section{RESUMO}

A doença falciforme é a afecção genética mais prevalente no Brasil; de acordo com o Programa Nacional de Triagem Neonatal (PNTN), nascem cerca de 3.500 (três mil e quinhentas) crianças por ano com hemoglobina $\mathrm{S}$, uma das responsáveis pela doença, ou seja, 1/1.0oo nascidos vivos no Brasil. Considerando o grau de sua incidência, é necessário observar o acesso à saúde possibilitado aos portadores dessa enfermidade, devendose analisar as dificuldades que afligem esse segmento populacional e a efetividade das políticas públicas existentes para enfrentamento dessa hemoglobinopatia. Por meio de metodologia descritiva e explicativa, constatou-se que o segmento social acometido por essa doença se encontra historicamente associado aos afrodescendentes, dada sua origem mutante no continente africano em resposta à disseminação da malária, fato que conjuga a enfermidade com os fatores raciais de discriminação histórica da população negra. A falciforme foi utilizada, em certos casos, como fundamento para exclusão dos negros da sociedade, como argumento para segregação racial nos Estados Unidos e como fundamento para ideia de embranquecimento da população brasileira.

Palavras-chave: Doença falciforme; Histórico; Políticas públicas; Direito à saúde; População negra. 


\section{ABSTRACT}

Sickle cell disease is the most prevalent genetic disorder in Brazil; according to the PNTN - Programa Nacional de Triagem Neonatal (National Neonatal Screening Program), approximately 3,500 (three thousand, five hundred) babies with haemoglobin disorders are born each year that is to say $1 / 1,000$ live-born in Brazil. Since the high degree of its incidence, it is necessary to observe how the access to the health is given to patients with this disease, and the difficulties that afflict this population segment and the effectiveness of existing public policies to confront this kind of genetic hemoglobinopath should be analyzed. Through descriptive and explanatory methodology, it was found that the social segment affected by this disease is historically associated with people of African descent, due to its mutant origin in the African continent in response to the spread of malaria, fact that combines the disease with the factors of historical discrimination against the Black population. Sickle cell disease, in certain cases, was used as a basis for exclusion of Black people from society, as an argument for racial segregation in the United States and as a basis for the idea of whitening the Brazilian population.

Keywords: Sickle cell disease; Historic; Public policy; Right to health; Black population.

\section{RESUMEN}

La anemia de células falciformes es el trastorno genético que prevalece en Brasil; según el PNTN - Programa Nacional de Triagem Neonatal (Programa Nacional de Detección Neonatal), aproximadamente 3500 (tres mil quinientos) niños nacen por año con una alteración de la sangre que causa esa enfermedad, o sea 1/1.00o nacidos vivos en Brasil. Teniendo en cuenta el grado de su incidencia, es necesario observar el acceso a la salud posibilitado a los portadores de la enfermedad, y se deben analizar las dificultades que afligen ese segmento de la población y la efectividad de las políticas públicas existentes para enfrentar esa hemoglobinoptía genética. A través de una metodología descriptiva y explicativa, se descubrió que el segmento social afectado por la enfermedad está históricamente asociado con los afrodescendientes, debido a su origen cambiante en el continente africano en respuesta a la propagación de la malaria, un hecho que combina la enfermedad con los factores de discriminación histórica de la población negra. La célula falciforme, en ciertos casos, ha sido utilizada como base para la exclusión de los negros de la sociedad, como argumento para la segregación racial en los Estados Unidos y como base para la idea de blanquear la población brasileña.

Palabras clave: Anemia de células falciformes; Historia; Políticas públicas; Derecho a la salud; Población negra.

INFORMAÇÕES DO ARTIGO

Contribuição dos autores:

Concepção e desenho do estudo: Edith Maria Barbosa Ramos e Paulo Henrique de Freitas Dutra Júnior. Aquisição, análise ou interpretação dos dados: Edith Maria Barbosa Ramos e Paulo Henrique de Freitas Dutra Júnior. Redação do manuscrito: Edith Maria Barbosa Ramos, Paulo Roberto Barbosa Ramas, Márcia Haydée Porto de Carvalho, Delmo Mattos da Silva e Paulo Henrique de Freitas Dutra Júnior.

Revisão crítica do conteúdo intelectual: Edith Maria Barbosa Ramos, Paulo Roberto Barbosa Ramas, Márcia Haydée Porto de Carvalho, Delmo Mattos da Silva e Paulo Henrique de Freitas Dutra Júnior.

Declaração de conflito de interesses: não há.

Fontes de financiamento: Fundação de Amparo da Pesquisa do Maranhão - FAPEMA e Universidade CEUMA - UNICEUMA.

Agradecimentos/Contribuições adicionais: Professoras Mestres Jaqueline Prazeres de Sena e Amanda Silva Madureira pela excelente coordenação do Núcleo de Atividades Complementares (NAC) da UNICEUMA. Conceição Sousa (Bibliotecária/UFMA) pelo auxílio com a revisão bibliográfica e de referências.

Histórico do artigo: submetido: 9 fev. 2020 | aceito: 14 jun. 2020 | publicado: 30 set. 2020.

Apresentação anterior: não houve

Licença CC BY-NC atribuição não comercial. Com essa licença é permitido acessar, baixar (download), copiar, imprimir, compartilhar, reutilizar e distribuir os artigos, desde que para uso não comercial e com a citação da fonte, conferindo os devidos créditos de autoria e menção à Reciis. Nesses casos, nenhuma permissão é necessária por parte dos autores ou dos editores. 


\section{INTRODUÇÃO}

A doença falciforme é a enfermidade genética que mais prevalece no Brasile acomete cerca de 3.500 (três mil e quinhentas) crianças por ano ou 1:100o (uma para cada mil nascidos vivos). Entre os estados brasileiros com maior incidência desta patologia genética encontram-se a Bahia, com proporção de 1:650 (um para cada seiscentos e cinquenta nascidos vivos); o Rio de Janeiro com 1:1.30o (um para cada mil e trezentos nascidos vivos); e, empatados com 1:1.40o (um para cada mil quatrocentos vivos), o Maranhão, Pernambuco, Minas Gerais e Goiás ${ }^{1}$.

Com o elevado índice de acometimento da doença nesses estados, segue também a hierarquização das estatísticas das unidades da federação com maior número de pessoas se autodeclarando pretas e pardas. De acordo com IBGE, na Pesquisa Nacional de Amostra de Domicílio Contínua², no ano de 2018, o Nordeste foi a região com maior crescimento da população negra, com 11,3\% da população autodeclarada como preta, e $63,2 \%$ autodeclarada como parda.

Desta forma, constata-se que na região Nordeste há predominância dos índices de reconhecimento autodeclarado da população preta e parda no Brasil e, como consequência, tem maior concentração de portadores desta hemoglobinopatia. Deve-se ressaltar, no entanto, os estados do Rio de Janeiro (Região Sudeste) com índice 9,9 \% de autodeclarada preta, e de Goiás (Região Centro-Oeste) com 53\% de predominância da população autodeclarada parda.

Por ser uma afecção genética, a falciforme não possui cura, somente tratamentos preventivos, por meio de aconselhamento genético e elaboração de planejamento familiar, além de tratamento das complicações da doença. A mutação genética nas hemácias é causa dessas complicações, pois, ao invés da forma de glóbulos, possuem formato de foice, o que ocasiona obstruções nos vasos sanguíneos, dificultando a circulação do sangue. Este fato acarreta lesões nos órgãos do indivíduo, desencadeando sintomas como: crises de dor; síndrome torácica aguda; febre; crise aplástica; crise de sequestração esplênica; complicações no fígado; vias biliares e icterícia; acidente vascular cerebral; úlcera de perna; infartos ósseos e problemáticas com a imunização devido à necessidade da retirada do baço.

Em razão da grande diversidade sintomatológica, há enorme dificuldade de diagnóstico dessa enfermidade, circunstância que se torna comum em virtude da pouca visibilidade e divulgação de informações sobre a doença. Percebe-se que a detecção dos portadores é frágil e inconsistente, o que resulta em altos índices de morbidade e mortalidade, mais precisamente na fase inicial da vida humana.

Diante da alta incidência da falciforme no Brasil e com as suas inúmeras complicações, é necessário que seja analisado o acesso à saúde possibilitado aos portadores dessa hemoglobinopatia, necessitando ponderar as características predominantes da população enferma, e, por ato contínuo, avaliar a evolução histórica dos aspectos sociais dos portadores dessa doença, para que se possa tracejar as dificuldades sofridas por estes, e por fim, averiguar se as políticas públicas existentes sanaram tais dificuldades históricas, efetivando na íntegra o real conceito de direito à saúde.

Em meio a história da falciforme, assim como da evolução histórica do direito à saúde no Brasil, os falcêmicos encontraram empecilhos na efetivação do direito sanitário, e somente com o movimento negro essa patologia genética obteve visibilidade perante o Estado que, em 16 de agosto de 2005, editou a Portaria No 1.391, instituindo a Política de Atenção Integral às Pessoas com Doença Falciforme e outras Hemoglobinopatias.

Documentos normativos nacionais e internacionais, modernamente, consideram o conceito de saúde como um status que vai além da ausência de doença, o que exige a análise de todos os parâmetros

\footnotetext{
i Segundo Werneck ${ }^{3}$ : "As reivindicações da população negra e de movimentos sociais - especialmente o Movimento de Mulheres Negras e do Movimento Negro - por mais e melhor acesso ao sistema de saúde participaram da esfera pública ao longo dos vários períodos da história das mobilizações negras, principalmente no período pós-abolição, e se intensificaram na segunda metade do século XX, com forte expressão nos movimentos populares de saúde, chegando a participar dos processos que geraram a Reforma Sanitária e a criação do Sistema Único de Saúde".
} 
conexos a uma vida saudável. Portanto, a análise profunda da evolução histórica da enfermidade atesta que os portadores da falciforme transportam uma carga estigmatizada, resultado de todo um conjunto de dificuldades político-econômicas e sociais sofridas pela população negra, visto que, no decorrer da evolução histórica, o racismo institucional é preponderante no atraso do avanço medicinal, e somado a estes pensamentos, o modelo privatista adotado no Brasil no período ditatorial auxiliou ainda mais a invisibilidade da enfermidade, acarretando a colocação dos negros às margens da sociedade, portanto, negando a estes o real gozo do direito a uma vida saudável.

Deve-se, ainda, considerar que as estruturas, os sistemas e as instituições não só podem incentivar contendas entre grupos raciais distintos, mas, não raro, podem configurar-se como a causa que engendra e solidifica o próprio racismo. Assim, o assassinato de um homem, uma mulher ou uma criança negra, pelo fato de serem negros, pode ensejar a aversão social à ação perpetrada pelo criminoso. No entanto, deve-se observar que a invisibilidade da anemia falciforme nas políticas públicas de saúde e nas pesquisas científicas representam uma forma mais discreta de racismo, embora tão perversa e injustificável como um assassinato.

Desse modo, com este artigo, pretende-se compreender a construção do sistema de direito e proteção às pessoas portadoras da falciforme, assim como perceber a articulação no processo de visibilização da enfermidade e a conquista de direitos pela população negra. Aborda, inicialmente, aspectos históricos em âmbito mundial, e, por fim, discute a condição do Brasil no que se refere às políticas públicas adotadas, no intuito de situar o direito à saúde no processo de constitucionalização dos direitos fundamentais sociais na Constituição da República brasileira de 1988. Realiza a discussão sobre a doença e suas configurações sociais ligadas aos negros, mais precisamente ao racismo institucional, discutindo a atribuição de responsabilidades de saúde ao poder público, a qual se dá de forma cogente, em especial para as populações mais vulneráveis.

Como metodologia, buscou-se mapear e discutir a produção acadêmica sobre o tema em diferentes prismas de conhecimento. Por meio de levantamento bibliográfico em base de dados, no final foram recuperados 21 artigos científicos sobre a temática. Realizou-se abordagem qualitativa, devido ao vínculo essencial existente entre o material em estudo e o tema em questão, e os dados obtidos dos materiais foram tratados por meio de análise documental. No entendimento de Gustin ${ }^{4}$, a pesquisa com abordagem qualitativa estuda os dados buscando seu significado, tendo como base a forma como se percebe, no estudo em questão, o fenômeno de visibilização da falciforme e dos direitos dos falcêmicos dentro do contexto do estado brasileiro de direito. Assim, ao utilizar a descrição qualitativa, procura-se analisar não só os aspectos aparentes do fenômeno, como também seus aspectos formadores, buscando explicar sua origem, relações e mudanças, e tentando intuir as consequências.

Quanto aos objetivos, a pesquisa foi desenvolvida de forma a buscar na bibliografia disponível o estado da arte sobre a relação entre o direito à saúde, o racismo, a enfermidade falciforme e os direitos médicos e sociais aos falcêmicos. Gustin ${ }^{4}$ pontua que: "A pesquisa qualitativa tem o ambiente natural como fonte direta de dados e o pesquisador como seu principal instrumento. [...] a pesquisa qualitativa supõe o contato direto e prolongado do pesquisador com o ambiente e a situação que está sendo investigada geralmente, por meio do trabalho intensivo".

No que diz respeito aos procedimentos técnicos, utilizou-se a pesquisa bibliográfica e documental. Gustin ${ }^{4}$ destaca que a pesquisa bibliográfica, em suma, é todo trabalho científico, porquanto toda pesquisa deve ter o apoio e o embasamento na pesquisa bibliográfica para que não se desperdice tempo com um problema que já foi solucionado e possa chegar a conclusões inovadoras.

Portanto, a pesquisa bibliográfica não é uma simples catalogação de tudo o que já foi escrito a respeito do tema, mas sim uma busca minuciosa de informações que se possa analisar de forma profunda o problema proposto, de modo que se chegue a uma resposta inovadora para o tema, mesmo que não seja uma resposta conclusiva, mas que sirva como meio para levar o leitor a refletir sobre a temática proposta. 
Por sua vez, a análise documental é indispensável na medida em que é realizada a partir de documentos, contemporâneos ou retrospectivos, considerados cientificamente autênticos. Desta feita, a análise documental constitui uma técnica importante na pesquisa qualitativa, seja complementando informações obtidas por outras técnicas, seja desvelando aspectos novos de um tema ou problema 5 .

\section{A ANEMIA FALCIFORME, SUA PATOLOGIA GENÉTICA E SEU HISTÓRICO MEDICINAL}

A falciforme manifesta-se de diversas maneiras, ou seja, a talassemia, traço falciforme e anemia falciforme, sendo as duas últimas as mais comuns entre seus portadores, ocorrendo quando um indivíduo herda de ambos os pais o gene da hemoglobina $\mathrm{S}(\mathrm{Hb} \mathrm{S})$, apresentando assim o genótipo $\mathrm{Hb} \mathrm{AS}$ no caso dos portadores do traço falciforme, e o genótipo $\mathrm{Hb}$ SS que caracteriza a anemia falciforme.

Sintomaticamente essa patologia se apresenta na anemia falciforme, visto que é no genótipo $\mathrm{Hb}$ SS que se tem a elevada taxa de hemoglobinas deformadas no organismo. É na hemoglobina que se encontra a alteração, que por um formato de glóbulo (forma normal) se altera para formato de foice (forma alterada pela enfermidade), por isso a nomenclatura 'falciforme'.

Na década de 1930 e 1940, a anemia falciforme foi vinculada à população negra, e foi frequentemente acrescida à visão de que a miscigenação entre negros e as demais raças provocavam uma epidemiologia particular de doença no país. Tal interpretação apresentou consonância com a ideia de que a singularidade do Brasil se explicava por sua grande população miscigenada. Diferentemente do período atual, em que há consenso científico sobre a origem africana da doença falciforme (DF $)^{\text {ii. }}$.

Nos artigos médicos sobre a anemia falciforme é comum mencionar o médico James Bryan Herrick, que publicando no Archives of Internal Medicine, em 1910, sugeriu, pela primeira vez, que hemácias falciformes seriam a causa dessa enfermidade. Herrick observou que os sintomas de seus pacientes, a febre, rinite crônica e aguda, aumento dos gânglios linfáticos, alterações cardíacas e cicatrizes nas pernas tinham padrões nas hemoglobinas dos pacientes, que possuíam hemácias em forma de foice. Tendo em vista que os sintomas clínicos observados não retratavam nenhuma doença já documentada, Herrick, em 1910, selecionou as condições hematológicas como a principal característica do quadro clínico de seus pacientes. ${ }^{7}$

Em 1935, o residente em cirurgia, Campbell ${ }^{8}$, advertiu sobre a necessidade de maior conscientização dos médicos acerca dos sintomas clínicos da anemia falciforme, pois muitos casos eram diagnosticados como apendicite ou outra enfermidade que causava dores abdominais.

A primeira publicação brasileira sobre anemia falciforme foi o artigo do médico Álvaro Serra de Castro publicado no Jornal de Pediatria, em 1934. O artigo resume-se à apresentação de cinco casos clínicos, provenientes de estudos empreendidos no Hospital São Francisco de Assis no Rio de Janeiro9.

A maior parte dos médicos que estudaram a anemia falciforme no Brasil nos anos 1930 e 1940 viu a enfermidade como uma doença importante para a saúde pública do país em vista da extensa população de negros e mestiços. Álvaro Serra de Castro ${ }^{9}$ salientou que a anemia falciforme representava um "problema médico-social" para o Brasil, uma vez que boa parte da população afetada pela doença é preta, e que, em decorrência do povo brasileiro em sua maioria ser negro, representava a "grande massa humana no país"; portanto, era preciso dar mais atenção a essa enfermidade. Gastão Rosenfeld ${ }^{10}$ apontou, em artigo na revista O Hospital, que o "nível econômico e cultural mais baixo" dos negros do país dificultava-lhes o recurso à medicina hospitalar e, portanto, contribuía para a escassez de estudos sobre a anemia falciforme no Brasil.

Entre pesquisadores que atentaram a realizar estatísticas sobre a incidência da anemia falciforme no Brasil, Ernani Silva destaca-se como o principal representante das pesquisas brasileiras relativas à doença

ii "A DF é uma enfermidade hereditária causada por uma hemoglobina mutante ligada à descendência de populações originárias principalmente da África subsaariana, e da Índia, da Arábia Saudita e de países mediterrâneos. [...] Os estudos de haplótipos - designação dada à sequência de DNA herdada dos pais - da HbS sugerem que o gene determinante dessa hemoglobina teve origem no ocidente centro-africano e que as migrações de populações ancestrais o dispersaram por todo aquele continente, chegando a algumas populações mediterrâneas"”. 
durante a década de 1940. Em meados desta década, ainda restavam dúvidas quanto à especificidade racial da falciforme. Uma das maneiras de dirimi-las foi a procura de hemácias falciformes em "grupos certamente isentos de miscigenação com elementos negroides" ${ }^{\prime 1}$. Como se supunha que certas comunidades indígenas ainda se mantinham isoladas, a procura de hemácias falciformes nesse grupo seria uma forma de averiguar a especificidade racial dessas hemácias. Nas análises de sangue feitas em 101 indígenas das etnias "caingangue e guaranis", Frimm ${ }^{12}$ não encontrou qualquer hemácia em forma de foice. A partir da sua coleta de dados, Ernani Silva se tornou o principal propagador do pensamento de que, no Brasil, as hemácias falciformes e a doença por elas causada possuíam aspectos epidemiológicos diferentes dos relacionados aos Estados Unidos, devido à diferente formação social dos negros brasileiros ${ }^{11}$.

O racismo institucional, de acordo com o Documento da Comission for Racial Equality coletivo de uma organização para prover um serviço apropriado e profissional para as pessoas por causa de sua cor, cultura, ou origem étnica" ${ }^{\prime 3}$. O racismo não possui origens atuais, pois, apesar da sua existência ainda na modernidade, suas origens encontram-se no final do século XV e início do século XVI, com o apogeu do mercantilismo europeu.

A estruturação racial no Brasil tem suas raízes na escravidão e na anulação dos valores da cultura africana pelos colonizadores. O cenário escravocrata durou por mais de três séculos e, apesar da extinção dessa modalidade de mão de obra, com o advento da Lei Áurea dando liberdades ao negro, persistia ainda no Brasil a ideologia da inferioridade de cor, institucionalizando o racismo excludente, pois os donos dos modos de produção econômica, em preconceito a pessoas pretas, respaldando-se nas teorias do determinismo social e do eugenismo ${ }^{\mathrm{iv}}$, empregavam imigrantes brancos com intuito de "branquear" o país ${ }^{v}$.

Com a falta de oferta de trabalho técnicos aos negros, sobrando somente labores de baixo valor econômico, o processo de marginalização tornou-se cada vez mais agressivo, como enfatizado por Moura ${ }^{\text {vi }}$ "pesando através do racismo ambíguo e dissimulado do brasileiro, a esmagar não apenas economicamente, mas, também, psicologicamente, cultural e existencialmente a grande população não branca para manter os seus níveis de privilégios."

Diante do panorama preconceituoso racial, instituiu-se a normalização da superioridade branca, principalmente daqueles que detêm o poderio estatal, como formuladores de políticas públicas, negando assim, qualquer alerta sanitário promovido por médicos pesquisadores que tentavam dar voz e visibilidade às mazelas da população preta, perpetuando este cenário até o período militar e sua decaída frente às reivindicações sociais.

\section{A LUTA PELO DIREITO À SAÚDE EM TERRAS BRASILEIRAS}

De acordo com Máximo ${ }^{17}$, pós-governo militar os gestores da sociedade civil começaram a possuir olhos para as doenças falciformes. O período militar foi empecilho para visibilidade da doença, em razão do modelo liberal seguido pelo Estado, que atribuía às empresas privadas as obrigações de regularem e de prestarem serviços de média e alta complexidade, reservando ao Estado somente a obrigação dos atendimentos básicos de saúde ou de baixa complexidade.

iii Documento da Comission for Racial Equality, 1999 apud ${ }^{13}$.

iv A teoria eugenista é a tese da evolução humana por meio da seleção genética da população, atribuindo como prioridade do Estado a extinção dos indivíduos débeis e criminosos, através da seletividade e "esterilização social". "Os discursos racistas e eugenistas atribuíram uma hereditariedade inferior aos brasileiros de origem africana. Diziam, inclusive, que a debilidade biológica dos negros era bem-vinda, pois, assim, o elemento inferior desapareceria na miscigenação. A parte boa prevaleceria. O campo eugênico brasileiro encampou a ideologia do branqueamento. A mestiçagem aliada com a imigração seletiva levaria ao embranquecimento da população brasileira e à depuração da raça' ${ }^{14 "}$.

v Para os detentores dos modos de produção, a contratação dos imigrantes europeus, brancos, respaldava-se no preconceito racial, justificando que o "negro livre não servia para trabalhar. A posição da marginalidade do negro em relação a esta nova configuração social seria, então, justificada através da ideia de inferioridade cultural da raça negra, característica responsável pela 'inadaptação' dos libertos a uma relação mais moderna de trabalho ${ }^{15}$ ".

vi Moura C. Sobrevivências do sistema escravista na estrutura da sociedade brasileira. D.O. Leitura. 1985; 4(42):14-15 apud ${ }^{16}$. 
Naquele período, as primeiras construções estatais do direito fundamental à saúde tiveram cunho autoritarista, pois durante a era militar, o Estado, forçosamente realizava, por meio dos exércitos de guardas sanitários, ações com determinações de erradicar os focos de mosquitos da febre-amarela ${ }^{17}$. Antes e durante o período militar de 1964, a saúde era vista como responsabilidade individual, de forma que as políticas sanitárias foram ineficazes, ou até mesmo inexistentes, deixando a população marginalizada, em sua maioria negros, sujeitos a uma 'loteria natural'.

Em 1920, tivera início a 'desmilitarização' das políticas sanitárias, com introdução de práticas educativas por Carlos Chagas, visando ao controle da tuberculose, das doenças venéreas e da hanseníase. Entretanto, devido aos interesses econômicos presentes na época, a atenção dessas tentativas de desmilitarização das políticas públicas voltara-se aos grandes centros urbanos promovedores da economia nacional, negando novamente à população com baixo poder aquisitivo a cobertura dessas políticas.

Os trabalhadores que se encontravam nas grandes cidades prestavam seus serviços de forma irregular e não raro em situações de precariedade sanitária; entretanto, a influência dos trabalhadores europeus (herança do racismo institucional do Estado em suas tentativas de 'branquear' a população brasileira) presentes em nosso território foi decisiva para a constituição de movimentos em busca de maiores qualidades nas assistências à saúde, surgindo diferentes processos de reivindicação no país. Na tentativa de sanar a problemática do período, um marco histórico no Brasil, principalmente no que diz respeito à Previdência Social, foi a instituição da que ficou conhecida como Lei Eloy Chaves. Apesar desta política de assistência à saúde possuir cunho privatista, foi um grande marco ao Estado brasileiro que contribuiu, pela primeira vez, para o financiamento sanitário ${ }^{18}$.

Com o advento do regime militar em 1964, novos modelos mercantilistas tomaram a frente das políticas públicas, conforme Máximo demonstra em sua dissertação: “A nova ordem vigente, altamente centralizadora e burocrática, provocou mudanças no modelo médico assistencial privatista vigente. Uma delas foi à criação do Instituto Nacional da Previdência Social (INPS) em 1966, em substituição aos IAPs. O INPS estendeu a cobertura previdenciária a praticamente toda a população urbana e rural, porém privilegiando as práticas individuais, curativas e especializadas através de prestadores privados, em detrimento das coletivas. Com isso o setor saúde foi firmado como altamente lucrativo consonante com o período conhecido como 'milagre econômico', dando início à mercantilização da assistência médica" ${ }^{17}$.

O modelo mercantilista proposto pelo governo militar trouxe regalias para o setor privado, por meio de altas taxas de financiamento, expandindo e modernizando os grandes hospitais. Conforme a política do Estado brasileiro, os beneficiários dos grandes serviços sanitários eram aqueles que faziam parte dos regimes empregatícios, deixando os serviços de baixo custo e de baixa qualidade voltados para a população pobre, em sua maioria, negros e pardos, pois estes não possuíam acesso às ofertas de empregos que poderiam viabilizar o gozo dos benefícios previdenciários. Máximo, destaca, ainda, que: "As atividades mais lucrativas, que envolviam procedimentos de alta complexidade e voltadas para as práticas curativas individuais ficaram a cargo do setor privado, sem qualquer integração com a banda não lucrativa, voltada para o coletivo, que ficou sob responsabilidade do Estado. Desta forma, não havia espaço para o discurso de promoção, prevenção e reabilitação da saúde da população de forma integrada e organizada em uma só política de Estado"”

Com o fim do 'milagre econômico' a classe formal trabalhadora perdeu seus empregos e os serviços previdenciários, e como não havia políticas públicas que oferecessem serviços de qualidade aos que não fossem empregados, o número de pobres e doentes no Brasil aumentou de forma exponencial. Gomes ${ }^{19}$ destaca que, no Brasil, o processo de transição política a partir dos anos 1980, desenvolvido numa conjuntura de agravamento das questões sociais e escassez de recursos, gerou impactos nas avaliações dos programas e revelou a necessidade de formulação de políticas sociais mais justas.

Somente após o aumento do número de desempregados e a queda das ofertas de trabalhos formais, exercidos em sua maioria pela população branca, tendo em vista a situação de exclusão dos negros e pardos, 
historicamente marginalizados pela instituição do racismo nos mais diversos setores sociais, notadamente os relacionados ao exercício do poder, foi que o Estado brasileiro começou a se articular para elaboração de políticas públicas sanitárias.

Abrolhando essas ocasiões, fervoraram-se no Brasil diversos movimentos em busca de mudanças no modelo privatista, com propostas de melhorias de qualidade na assistência à saúde, tendo como um dos maiores pontos relevantes a busca da equidade de atendimentos em centros urbanos e rurais, com modelos voltados para atendimento coletivo e com tutela do poder público.

A Constituição da República Federativa do Brasil de 1988 trouxe na tríade da Seguridade Social, o direito à saúde, definindo-a como um "direito de todos e dever do Estado, garantido mediante políticas sociais e econômicas que visem à redução do risco de doença e de outros agravos e ao acesso universal e igualitário às ações e serviços para sua promoção, proteção e recuperação"2o. Além do conceito mais amplo relacionado ao direito à saúde, a Carta Magna brasileira inovou trazendo o Sistema Único de Saúde (SUS). Ramos e Diniz destacam que: "A Constituição Federal de 1988 foi o primeiro texto constitucional brasileiro a tratar a saúde como direito, inserindo-a no sistema da seguridade social" ${ }^{21}$, que, por sua vez, "compreende um conjunto integrado de ações de iniciativa dos Poderes Públicos e da sociedade, destinadas a assegurar os direitos relativos à saúde, à previdência e à assistência social”22. Ao contrário da previdência (de caráter contributivo) e da assistência social (prestada a quem está em situação de necessidade), a saúde se pauta pelo acesso universal, como se vê na citação de artigo da Constituição no inicio deste parágrafo.

A regulamentação do SUS ocorreu somente em 1990, com a Lei No 8.080, definindo sua organização legal e institucional, inclusive a sua gestão de recursos. Entretanto, apesar da teoria que cerca o Sistema Único de Saúde, na práxis, no momento de instauração desse sistema, o Brasil encontrava-se em crise fiscal, dificultando ainda mais a concretização das políticas públicas sanitárias. Assim, Máximo ressalta que: "Foi criado um terreno fértil para a proliferação de práticas neoliberais e para a instituição de um estado mínimo, como a focalização de ações em saúde para as camadas mais pobres e menos organizadas da população e a priorização de ações de baixo custo. O efeito produzido ao longo da década de 1990 foi a oferta de serviços de baixa qualidade pelo sistema público, a modernização do setor privado, levando à expansão da medicina suplementar e a preponderância de um modelo neoliberal privatizante." ${ }^{, 17}$

Em razão de toda essa operação instalada na seara sanitária, empresas privadas de planos de saúde, aproveitaram-se para deixar seus serviços mais baratos e acessíveis à classe média, mas, em contrapartida, o cidadão deveria submeter-se às normas impostas nos contratos, dependendo novamente dos veículos privados para usufruir do seu direito à saúde, o que conduziu novamente o Brasil a um cenário de desigualdade de acesso aos serviços médico e de saúde e institucionalizando, definitivamente, o universalismo excludente.

Diante dessas tessituras, deve-se ressaltar a argumentação desenvolvida por Silva ${ }^{22}$, ao compreender que toda política pública é uma forma de regulação ou intervenção na sociedade. Articula diferentes sujeitos, que apresentam interesses e expectativas diversas. Constitui um conjunto de ações e omissões do Estado, decorrente de decisões e não decisões, constituído por jogos de interesses, tendo como limites e condicionamentos os processos econômicos, políticos e sociais.

Silva $^{22}$ destaca, ainda, que a diversidade de sujeitos sociais e de racionalidades conduzem, necessariamente, a desencontros, embates e conflitos na medida em que se tem diferentes interesses, diferentes competências e papéis, produzindo diferenciação da perspectiva de tempo que orienta cada racionalidade, sendo difícil o estabelecimento de limites e de consenso. Todavia, para que seja possível o desenvolvimento do processo das políticas públicas, são necessárias a compreensão e a compatibilização de funções e papéis, sendo indispensável a construção de consenso em aspectos centrais desse processo, principalmente no que se refere à aceitação das prioridades estabelecidas no plano político, informacional, e aos meios de produção econômica. 
No cenário das políticas públicas, e das medidas necessárias para o combate à falciforme, a dimensão do racismo mais presente, é a institucional, pois "atua de forma a induzir, manter e condicionar a organização e ação do Estado, suas instituições e políticas públicas - atuando também nas instituições privadas - produzindo e reproduzindo a hierarquia racial [...] capaz de gerar e legitimar condutas excludentes tanto no que se refere a formas de governo quanto de accountability."3

Diante da existência do racismo institucional, o Estado, apesar de adotar em seus instrumentos normativos o conceito de saúde, na práxis, não o aplica. De acordo com Ramos: "A consideração do direito à saúde dos indivíduos e sua proteção aparece fortemente vinculada com aspectos relativos ao nível e as condições de vida da população. Além disso, os serviços médicos de saúde aparecem apenas como um dos elementos integrantes do direito à saúde, mas não o único”²3.

Apesar de não haver consenso ${ }^{23}$ acerca do conceito do que seja o "direito à saúde", já se entende que o vai muito além da simples ausência de doença, abarcando diversos outros fatores que possibilitam fornecer condições saudáveis ao ser humano, desde o combate às enfermidades, até os cuidados relativos à salubridade e às condições socioeconômicas dos indivíduos e das populações mais vulneráveis.

Após essas observações, deve-se compreender que as políticas públicas que atendem aos portadores da doença falciforme devem abarcar o conceito mais abrangente de saúde, visto que, "quando se compreende a saúde ou a doença como uma mera circunstância, como uma espécie de loteria natural independente de considerações sobre a estrutura social ou institucional, a ausência de saúde não poderia ser considerada como uma situação de injustiça $[. . .]^{\prime 23}$.

De acordo com o art. 12 do Pacto Internacional sobre os Direitos Econômicos, Sociais e Culturais, o direito à saúde é reconhecido como "[...] o direito de cada pessoa a desfrutar do mais alto nível possível de saúde física e mental." ${ }^{24}$ Por ser um direito fundamental de segunda dimensão, a saúde impõe uma prestação positiva ao Estado, no sentido de fazer algo de natureza social em favor do homem. Aqui encontramos os direitos relacionados “[...] sob a proteção da situação de doença e velhice.”25

Dados do Ipea demonstram que a população de origem afrodescendente está sobrerepresentada na população mais pobre do Brasil, condição que incrementa o cenário atual de invisibilidade da hemoglobinopatia que a acomete. A população acometida por esta patologia genética possui baixa escolaridade, remuneração de até dois salários mínimos, e devido às complicações da enfermidade acaba por possuir baixo poder competitivo no mercado de trabalho ${ }^{26}$.

Além do fator socioeconômico, as políticas públicas voltadas ao enfrentamento dessa hemoglobinopatia possuem elevadas problemáticas quanto ao diagnóstico do número de portadores no Brasil, devido à inexistência de uma rede estruturada que avalie os índices de mortalidade e letalidade da doença falciforme. A inexistência de informação nos atestados de óbito, a ausência de cadastros informatizados nos centros de referência e hemocentros e a existência de população sem diagnóstico revelam a necessidade de estruturação de uma rede de informações sobre essa doença para que se possa avaliar o impacto das políticas implementadas com o objetivo de garantir o acesso ao direito à saúde no segmento populacional acometido especificamente por essa enfermidade.

\section{CONSIDERAÇÕES FINAIS}

O direito à saúde em sua conceituação mais moderna, bebendo diretamente dos tratados e pactos internacionais que versam sobre o direito sanitário, assim como da própria Constituição da República Federativa do Brasil, significa o direito do indivíduo e dos grupos populacionais, tanto na seara particular como na coletiva, possuir uma vida saudável, desde a ausência de doença às condições dignas de subsistência, como a garantia de direito à segurança, educação, ao lazer, à infraestrutura entre os demais direitos fundamentais inerentes ao ser humano. 
Além da sua conceituação, faz-se necessário mencionar a classificação do direito à saúde no rol dos direitos fundamentais, apesar da doutrina moderna, acertadamente classificar tal direito incluindo diversas dimensões, haja vista, como já mencionado, ele abarca uma gama de diversos outros direitos, como a liberdade, e até a mesmo a fraternidade. Em sua síntese, o direito à saúde é tratado como direito fundamental de segunda dimensão, ou seja, cria a condição de dever positivo de agir do Estado, fornecendo meios que garantam o acesso da sociedade a usufruir dos seus direitos, seja por meio das garantias fundamentais, seja mediante a implementação de políticas públicas.

As políticas públicas proporcionam meios de efetivação e garantia de direitos à população, ou a um determinado grupo específico que, caso não seja atendido, terá toda a sociedade civil impactada negativamente. Entre tais grupos especiais, os portadores da anemia falciforme necessitam de atendimentos excepcionais, e políticas públicas peculiares que visem atenuar o sofrimento desses pacientes. Além disso, deve-se pôr em relevo que a doença falciforme é a doença genética que mais prevalece, no Brasil, e acomete milhares de brasileiros, em sua maioria negros e pardos, que, por motivos históricos raciais e pela institucionalização do racismo, se encontram à margem da sociedade brasileira, tendo em vista que, em sua maioria, são pessoas em situação socioeconômica de vulnerabilidade.

A Política de Atenção Integral a Pessoas com Doença Falciforme e outras Hemoglobinopatias representou uma grande conquista. Entretanto, apesar da sua criação, essa política pública não faz qualquer menção à situação em que se encontram os portadores dessa patologia genética, deixando de lado o aspecto ampliativo do direito à saúde.

Além do fator socioeconômico e racial, a política pública não possui uma rede estruturada de estatísticas que possam auxiliar os gestores na efetivação, ampliação e até mesmo na criação de novas políticas públicas. A ausência de registro nos cadastros de óbito, e da informação se a morte teve relações diretas ou indiretas com a doença, assim como a inexistência de estatísticas do número de pacientes acompanhados e frequentadores dos centros de hemoterapia e sobre quais os motivos que o fazem desistir do tratamento, ou continuar em busca do tratamento são somente alguns exemplos das falhas e dificuldades estruturais da política pública.

Conclui-se, portanto, que atualmente há necessidade de se buscar mecanismos mais eficazes para a visibilização da doença falciforme, combatendo os determinantes sociais impostos à população negra, que historicamente é sobrepujada pelo Estado, e que, via de regra, está demarcada pelo racismo institucional determinante da exclusão dos seus direitos. É preciso também uma melhor sistematização das informações sobre a enfermidade e sobre as condições de vida e morte dos falcêmicos, bem como necessita-se de maior articulação das políticas públicas para enfrentamento da enfermidade, de tal forma que os pacientes possam ter acompanhamento e ambiente adequado nos centros de hemoterapia e nas suas comunidades em geral.

\section{REFERÊNCIAS}

1. Ministério da Saúde (BR). Secretaria de Atenção a Saúde. Departamento de Atenção Especializada. Doença falciforme: condutas básicas para tratamento. Brasília, DF: Ministério da Saúde; 2012.

2. Barbosa B. Número de brasileiros que se declaram pretos cresce no país, diz IBGE. Notícias UOL [Internet]. 2019 [citado em 2020 jun. 23]. Disponível em: https://noticias.uol.com.br/cotidiano/ultimasnoticias/2019/05/22/ibge-em-todas-as-regioes-mais-brasileiros-se-declaram-pretos.htm.

3. Werneck J. Racismo institucional e saúde da população negra. Saúde Soc [Internet]. 2016 [citado em 2020 mar. 5];25(3):535-49. Disponível em: https://www.scielo.br/pdf/sausoc/v25n3/1984-0470sausoc-25-03-00535.pdf.

4. Gustin MBS, Dias MTF. (Re) pensando a pesquisa jurídica: teoria e prática. Belo Horizonte: Del Rey; 2013.

5. Lüdke M, André MEDA. Pesquisa em educação: abordagens qualitativas. São Paulo: EPU; 1986. 
6. Ministério da Saúde (BR). Doença falciforme: diretrizes básicas da linha de cuidado [Internet]. Brasília, DF. 2015 [citado em 2018 set. 3]. Disponível em: http://bvsms.saude.gov.br/bvs/publicacoes/doenca falciforme diretrizes basicas linha cuidado.pdf.

7. $\quad$ Castilhos LG, Schlemmer JB, Lima SBS. Atenção primária e doença falciforme: uma revisão sobre o papel do gestor. Saúde [Internet]. 2016 [citado em 2018 set. 3];42(sup):45-52. Disponível em: https:// periodicos.ufsm.br/revistasaude/article/view/15072. doi: http://dx.doi.org/10.5902/2236583415072.

8. Campbell EH. Acute abdominal pain in sickle cell anemia. Archives of Surgery. 1935;31:607-21.

9. Castro AS. A eritrofalcemia: doença falciforme latente e ativa [tese]. Rio de Janeiro: Faculdade de Medicina da Universidade do Brasil; 1944.

10. Rosenfeld G. Anemia drepanocítica (falciforme): um caso de anemia e outro de drepanocitemia considerações sobre a denominação da moléstia. O Hospital. 1944;25(6):845-54.

11. Silva EM. Estudos sobre índice de siclemia. Memórias do Instituto Oswaldo Cruz. 1945;42(2):315-40.

12. Frimm CE. A drepanocitose: clínica e patologia da anemia drepanocítica e da drepanocitemia [tese]. Porto Alegre: Faculdade de Medicina, Universidade do Rio Grande do Sul; 1947.

13. Sampaio E. Racismo institucional: desenvolvimento social e políticas públicas de caráter afirmativo no Brasil. Interações - Revista Internacional de Desenvolvimento Local. 2003; 4(6):77-83.

14. Santana NMC, Santos RA. Projetos de modernidade: autoritarismo, eugenia e racismo no Brasil do século XX. Revista de Estudios Sociales [Internet]. 2016 [citado em 2019 abr. 20];(58):28-38. Disponível em: http://journals.openedition.org/revestudsoc/295.

15. Rolnik, R. Territórios negros em São Paulo. Folha de S. Paulo.1986; 28 set; Folhetim (503):2-4.

16. Kalckmann S, Santos CG, Batista LE, Cruz VM. Racismo institucional: um desafio para a equidade no SUS? Saúde Soc. 2007;16(2):146-55.

17. Máximo C. A política de atenção integral à pessoa com doença falciforme no estado do Rio de Janeiro e os desafios da descentralização [dissertação]. Rio de Janeiro: Departamento de Ciências Sociais, Escola Nacional de Saúde Pública, Fundação Oswaldo Cruz; 2009.

18. Mendes EV. As políticas de saúde no Brasil nos anos 80: a conformação da reforma sanitária e a construção da hegemonia do projeto neoliberal. In: Mendes EV. Distrito Sanitário: processo social de mudança das práticas do sistema único de saúde. São Paulo: Hucitec; 1993; p. 19-91.

19. Gomes MFCM. Aspectos teóricos metodológicos da pesquisa avaliativa. In: Silva MOS, organizador. Avaliação de políticas e programas sociais: teoria e prática. São Paulo: Vozes; 2001.

20. Brasil. Constituição (1988). Presidência da República. Senado Federal. Constituição da República Federativa do Brasil (1988). Brasília, DF: Imprensa Oficial; 1988.

21. Ramos EMB, Diniz IM. Breve reflexão sobre a construção da ideia de proteção social e o direito à saúde na Constituição Federal de 1988. RCGD. 2016 [citado em 2019 abr. 20];9(2):66-84. Disponível em: https://periodicos.ufrn.br/constituicaoegarantiadedireitos/article/view/12254/8483.

22. Silva MOS, organizador. Avaliação de políticas e programas sociais: teoria e prática. São Paulo: Vozes; 2001.

23. Ramos EMB. Universalidade do direito a saúde. São Luís: Edufma; 2014.

24. ONU. Pacto Internacional de direitos econômicos, sociais e culturais [Internet]. 1996 [citado em 2018 out. 8]. Disponível em: http://www.planalto.gov.br/ccivil_03/decreto/1990-1994/d0591.htm.

25. Bulos UL. Curso de Direito Constitucional. 9. ed. São Paulo: Saraiva; 2015.

26. Bragion GKP, Costa CMS, Viana EC. Aspectos sociais dos pacientes com úlcera de perna na doença falciforme: revisão integrativa. Rev Enferm Cent.-Oeste Min. 2017 [citado em 2018 out. 8];7:e1470. doi: http://dx.doi.org/10.19175/recom.v7i0.1470. 